\title{
Paradigmas, valores e educação
}

Denis Domeneghetti Badia

Universidade Estadual Paulista

\section{Resumo}

0 texto levanta os perfis epistemológico e socianalítico da questão paradigmática. Mauss evidenciara o moule affectif das noções científicas de força e causa. Posteriormente Baudouin falaria na indução arquetípica das noções e a antropologia do imaginário de Durand concluiria pela indução arquetipal do conceito pela imagem. Chegava-se, assim, ao desvendamento do substrato inconsciente das ideações, de um substrato regido pela catexis vetorializada, traduzindo-se nos valores como cerne das ideações. É o famoso a priori emotivo. Portanto, no texto, questionam-se dois mitos, esteios da ciência clássica: o mito da objetividade científica e o da neutralidade axiológica. Destaca, assim, a falácia da existência de uma ruptura epistemológica entre ciência e ideologia. A partir daí, as ideações tornam-se ideologias, sobretudo nas ciências do homem e nas ciências da educação que, ademais, tornam-se suporte de uma disfarçada luta ideológica, na qual, num "colonialismo cognitivo", as estratégias de conhecimento dissimulam as de preconceito. Entretanto, assumir a realidade desse suporte fantasmanalítico e ideológico propicia uma tarefa educativa salutar: os paradigmas tornam-se fantasias e, nessa relativização crítica, podem ser usados como um campo de objetos transicionais coletivos num ludismo cultural e educativo. No policulturalismo da sociedade contemporânea, o "politeísmo de valores" de Weber transforma-se num "politeísmo epistemológico", regido pelo "relativismo ontológico" de Feyerabend e por uma ética do pragmatismo. Articulando cultura, organização e educação, a antropologia das organizações educativas e a culturanálise de grupos de Paula Carvalho traduzem as heurísticas dessa dialética transicional.

\section{Palavras-chave}

Questão paradigmática - Axiologia - Fantasmanálise - Ação educativa.

Correspondência: 


\title{
Paradigms, values and education
}

Denis Domeneghetti Badia

Universidade Estadual Paulista

\begin{abstract}
The text draws the epistemological and socioanalytic profiles of the paradigmatic question. Mauss evinced the moule affectif of the scientific notions of force and cause. Later, Baudouin would speak of the archetypical induction of the notions, and Durand's anthropology of the imaginary would conclude for the archetypical induction of the concept by the image. That was the unveiling of the unconscious substrate of ideations, of a substrate governed by the vectorialized cathexis translated into values as the kernel of ideations. It is the famous emotive a priori. The text therefore questions two myths, mainstays of classical science: the myth of scientific objectivity, and that of axiological neutrality. It brings forward the fallacy of the existence of an epistemological rupture between science and ideology. Henceforth, ideations become ideologies, particularly in the sciences of Man and in the sciences of education which, in addition to that, are made to give support to a hidden ideological struggle in which the knowledge strategies, in a "cognitive colonialism", conceal those of prejudice. At any rate, assuming the reality of this phantasmanalytic and ideological support allows a salutary educative task: paradigms become fantasies and, in this critical relativization, can be used as a field of collective transitional objects in a cultural and educative gameness. In the polyculturalism of contemporary society, Weber's "polytheism of values" becomes an "epistemological polytheism" governed by Feyerabend's "ontological relativism" and by an ethics of pragmatism. Articulating culture, organization and education, the anthropology of educational organizations and the group culturanalysis of Paula Carvalho represent the heuristics of this transitional dialectics.
\end{abstract}

\section{Keywords}

Paradigmatic question - Axiology - Phantasmanalysis - Educative action.

Contact:

Denis Domeneghetti Badia

Depto de Ciências da Educação

UNESP - Campus de Araraquara

Rodovia Araraquara - Jaú - Km 01

14800-901 - Araraquara - SP 
Segundo Toulmin (1973), a palavra paradigma começa a ser utilizada no domínio da ciência por Lichtenberg em meados do século XVIII, precisamente no momento em que também vai ser adotada pela linguística da época, dada a necessidade de encontrar modelos de conjugação e declinação no âmago da linguagem. Em física, dava-se o mesmo: tratava-se de reduzir certos fenômenos insólitos a modelos que definissem determinada racionalidade. De acordo com Prado Coelho (1982), "questões de arranjo [...] o paradigma é um fator de ordem e de ordenação" (p. 27). 0 uso do termo permanece discreto. Certa apatia acontece até o final do século $\mathrm{XIX}$, até que Lichtenberg começa a ser lido e a influenciar a nova filosofia da ciência como, por exemplo, o empiriocriticismo de Mach. Com a leitura de Lichtenberg, emerge o termo adentrando o cenário científico. 0 paradigma entra novamente em cena filosófica por meio de Wittgenstein entre 1938 e 1947.

Por volta dos anos 1950, chegava aos Estados Unidos. Nessa época, Kuhn (2000), homem de formação científica, começava a se interessar pela filosofia, posteriormente, de modo mais específico, pela história e filosofia da ciência. Ele se refere às obras importantes de Koyré, Meyerson, Metzger (cuja influência sobre Bachelard é decisiva) e Maier. No entanto, a formação filosófica de Kuhn terá ainda outros componentes: os trabalhos de Piaget, sobretudo no domínio da psicologia da percepção; as concepções de Lee-Whorf, estabelecendo as bases de um relativismo linguístico (cada linguagem determina uma concepção de mundo, que condiciona os que nela falam); as análises de Quine sobre o empirismo e seus dogmas; os estudos de história da cultura de Lovejoy; e os ensaios de Fleck sobre a importância dos grupos científicos. Kuhn vai traçar os primeiros esboços de suas futuras ideias a partir de 1951 na série de Conferências do Instituto Lowell de Boston. Em 1957, publica The copernican revolution. Ao final dos anos 1950, iria se impor a ideia de paradigma.

Entretanto, agora o termo paradigma está fortemente associado à passagem de uma concepção de história em moldes de conti- nuidade para uma concepção em moldes de descontinuidade. Nesse sentido (e só nesse, pois no resto muitas são as diferenças), pode-se dizer que a noção de paradigma pertence à complexa família dos "jogos de linguagem" de Wittgenstein (1961), das "realidades múltiplas" de Schütz (1972; 1978), das "realidades alternativas" de Castaneda, das "estruturas da linguagem" de Lee-Whorf, das "problemáticas" de Bachelard (1934; 1975) ou dos "epistemas" de Foucault (apud Giddens, 1978). Em todas essas noções, existe a ideia de que o nosso mundo se multiplica noutros mundos mais ou menos autônomos, seja ao longo do processo histórico ou seja na própria textura do presente que nos envolve. A separação entre esses mundos, sua relativa incomunicabilidade, os problemas da tradução entre si e a (im)possibilidade de encontrarmos um mundo estável e objetivo, que se torne padrão de avaliação de todos os outros, são algumas das questões que pervagam o uso da noção de paradigma. Diante dessa problemática, segundo Prado Coelho (1982), duas reações são possíveis:

1. ou se aceita a diversidade do real, acabando por dissolver nela todas as referências estáveis;

2. ou se considera que essa diversidade é apenas aparência e oculta um nível subjacente de padrões absolutos. (p. 28)

Iremos, assim, oscilando entre o relativismo e a absolutização, ou seja, em termos do século XX, entre Collingwood $(1940 ; 1978)$ e Frege (1971) como vetores respectivos dessas orientações de sentido. Respectivamente com a holonomia, teríamos, por um lado, o equivalente dessa polêmica nas discussões entre Prigogine (Petitot, 1988) e a Escola de Bruxelas - nos vetores de Bachelard $(1934 ; 1975)$ e de Morin (2000) e, por outro lado, a "teoria das catástrofes" e a topologia de Thom (Petitot, 1988), próximas a uma arquetipologia.

Frege (1971) afirmava que se quisermos conhecer o mundo, não podemos reduzi-lo a um mero fluxo de fenômenos, pois precisamos 
crer em coisas estáveis, que persistem sob as mudanças e transformações. Essa estabilidade encontra-se nos puros conceitos quando somos capazes de pensá-los em si mesmos, libertos das sedimentações históricas que os envolve. Se os conceitos têm uma história, trata-se apenas da história de como nós os conhecemos, não da história dos próprios conceitos, que subsistem numa esfera intemporal do entendimento. A tarefa da filosofia consiste em apreender a forma pura do conceito: por isso, ele orienta seus estudos para os domínios da lógica e da matemática.

Collingwood $(1940 ; 1978)$ situa-se no polo oposto da antinomia absoluto-relativo. Para Prado Coelho (1982), entretanto, esse relativismo de Collingwood nada tem a ver com o subjetivismo contemporâneo ou o modo contemporâneo do solipsismo epistemológico como, por exemplo, assumido por Foerster (1974). A diversidade, ou a diferença, conceitual é um ponto de partida objetivo da reflexão de Collingwood. 0 que está tematizado, no caso de Frege (1971), é a existência de um estrato conceitual intemporal e absoluto capaz de servir como referência, sem controvérsias, para a avaliação de todos os outros estratos e incidências. A célebre distinção entre Sinn e Bedeutung, nos Escritos lógicos e filosóficos, que é densamente discutida por Rusell (1990), não terá outra finalidade.

A experiência conceitual de Collingwood não autoriza admitir isso. Se queremos fazer um julgamento, emitir um juízo sobre uma teoria, temos como único padrão objetivo o próprio conjunto de valores do quadro cultural a que essa teoria pertence e nada além disso. Collingwood (1940) parte da estrutura tradicional das teorias científicas, tal como entendida pela filosofia de seu tempo. Uma teoria é constituída por um sistema de proposições entre si vinculadas por uma rede de relações lógicas. De um ponto de vista empirista, essas relações se dão de baixo para cima, isto é, os enunciados teóricos produzem-se a partir dos enunciados de observação, partindo-se do fato para a lei, do dado para a abstração. É a clássica descrição da indução. De um ponto de vista racionalista, as relações se dão de cima para baixo, isto é, temos axiomas, princípios e leis gerais que possibilitam o entendimento dos enunciados de observação. É a clássica descrição da dedução. De qualquer modo, o sistema teórico é sempre um sistema de relações lógicas entre proposições. Collingwood (1978) dirá que isso só serve para a matemática. Diz ainda que não encontra nos outros domínios do conhecimento essa linearidade axiomática e vai explicar isso:

1. entre os enunciados da teoria as relações não serão relações de verdade, mas relações de significado ou sentido: cada enunciado interpreta-se noutros, e assim vai se tecendo o texto do significado e o tecido da significância. Mas nenhum enunciado garante ou avaliza a verdade dos outros. Há apenas um significado em construção. Ou um processo de significância ou significatividade;

2. esse significado, esse sentido, essa significância ou significatividade se constroem não sob a forma de sistema axiomático, mas em forma de rede de pressuposições. (p. 62)

É a partir da concepção da teoria como sistema formado por redes de pressuposições e relações de significado que Collingwood chegará à conclusão que, em qualquer teoria, quaisquer enunciados pressupõem outros enunciados mais gerais que os fundamentam e justificam. São esses enunciados mais gerais que asseguram a eficácia lógica dos demais. No entanto, onde isso para?

Cada enunciado estabelece relações com os enunciados adjacentes e com aqueles mais particulares a que ele dá fundamento. Entretanto, estabelece também com aqueles que estão mais acima e lhe dão uma razão de ser. Contudo, no termo da hierarquização, quem manda? Collingwood dirá que é um sistema de pressuposições absolutas, e isso será o paradigma.

De modo denso e minucioso, Prado Coelho (1982) mostra que a problemática epistemológica do paradigma, da década de 1960, 
configurando-se, sobretudo, por meio da polêmica em torno da obra de Kuhn, A estrutura das revoluções científicas, publicada em 1962, é uma aprofundada retomada da problemática tematizada, na década de 1940, pelo Ensaio de metafísica, de Collingwood, Herdeiro da tradição do relativismo epistemológico de Sócrates e Montaigne, opondo-se, portanto, ao enfoque de Descartes e, no século XX, aos Escritos lógicos e filosóficos de Frege, interessa-nos os resultados a que chega Collingwood ao conceber o paradigma como "um sistema de pressuposições absolutas" e, no contexto racionalista da problemática paradigmática, apresentar o insight, de extrema significação, ao conceber que o solo do paradigma (sobretudo no que diz respeito a "mudança ou salto paradigmático") é um processo de pensamento inconsciente.

De modo ignaro, Toulmin (1977) retoma as linhas de sua intervenção no Simpósio de 1970, organizado por Lakatos (1979), e, numa perfeita ilustração de ignorância por hybris epistemológica, afirma que pensamento inconsciente é uma expressão absurda e contraditória, sobretudo quando Collingwood dela se vale para resolver a questão que Kuhn chamaria de incomensurabilidade e de incomunicabilidade na questão paradigmática, especialmente na questão do salto paradigmático, questões onde se evidencia o "paradigma como sistema de pressuposições absolutas”. Entretanto Toulmin, como epistemólogo, desconhece a Escola de Genebra, ou seja, a psicologia complexa e a psicocrítica com as elaborações de Baudouin (1963) e de Mauron (1968). Ora, esse autor define e explora a noção de pensamento inconsciente, que será uma densa fundamentação para aquilo que, no livro $A$ imaginação científica, de Holton (1989), o autor designaria como themata ou as metáforas obsessivas e as matrizes arquetipais inconscientes recorrentes no evolver do pensamento científico, descoberta essa que Morin (2000) capilariza em Ciência com consciência, em seu Capítulo 2, que traz o expressivo título de " 0 conhecimento do conhecimento científico", e que desponta na questão candente da criatividade científica em oposição ao pensamento operacional. Mauron (2000) adverte o leitor cartesiano, adepto de um pensamento racionalista e formalista que se choca com essa noção, que

[...] o pensamento é o ato mental pelo qual quaisquer representações são comparadas, religadas, agrupadas, de modo que tal ato pode ser inconsciente e se distingue, assim, do pensamento propriamente reflexivo. (p. 31)

Vale-se, ainda, da noção de "função oscilante", elaborada por Kris (1953) e Bellack (1961), que possibilita, tanto para o artista, quanto para o cientista, "saltar" entre os universos consciente e inconsciente. Mais uma vez, isso é de extrema importância na questão da criatividade científica pela emergência/enação dos themata na criatividade científica.

Após essa mise-au-point, voltemos a Collingwood, que Kuhn (2000) retoma, sem explícita menção, ao longo de todo o Posfácio. Assim, o paradigma é um sistema de pressuposições absolutas do teor de um pensamento inconsciente, ou seja, um sistema de pressupostos absolutos, significando um sistema de sentimentos e valores, modos de pensar, ver, falar e argumentar que introduz o relativismo epistemológico e o pensamento da diferença, que Kuhn herda (apesar de se debater contra). Um antropólogo como Geertz (2001) soube avaliar isso melhor que qualquer epistemólogo no capítulo "0 legado de Thomas Kuhn: o texto certo na hora certa”, do livro Nova luz sobre a Antropologia.

Kuhn coloca a questão de como proceder quando se configura uma não comensurabilidade de estruturas de pensamento, que não podem ser resolvidas seja pela confrontação paradigmática de universos diferentes, seja pela "tradução", o que fará ressaltar de modo irredutível o paradigma como uma estrutura de pensamento, linguagem e visão de mundo estreitamente vinculada a um grupo (comunidade científica ou intragrupos da comunidade científica) e à defesa de um sistema de valores e crenças. Assim, advindo a questão 
das matrizes socioantropológicas e antropopsicanalíticas dos paradigmas e epistemas, Kuhn repete, disfarçando e amortecendo, os efeitos daquilo que Collingwood assume às claras. Vejamos isso em Collingwood e, depois, vinculemo-lo a Kuhn.

Collingwood (1940) diz que se compreendermos o paradigma como um sistema de pressuposições absolutas, a que acrescentaríamos do teor de um pensamento inconsciente, há dois modos, como sintetiza Prado Coelho (1982), de incomunicabilidade que o paradigma define.

[...] em primeiro lugar, eu não posso confrontar enunciados cujo significado depende de sistema de pressuposições diferentes. Há aqui universos que se incompatibilizam. Em segundo lugar, eu não posso comparar um sistema de pressuposições absolutas com outro sistema de pressuposições absolutas. Porque, onde está o espaço neutro (sem pressuposições) para as por em confrontos e avaliar? É a própria linha da racionalidade que se fratura nesta multiplicidade de mundos incomparáveis. (p. 30)

É a mesma ideia que, em a Fenomenologia do mundo social e em Collected Papers, Schütz defenderá, na linhagem de James, sobre as realidades múltiplas, definindo-as como âmbitos finitos de sentido, de modo que são "pluri(uni)versos", onde cada um "habita" e cuja transversalização e cruzamento é altamente problemática, pois são mundos diferentes ou "mundividências" diferentes, onde só a comoção permite o "salto paradigmático" - perceba o teor emotivo e inconsciente do termo "comoção": os franceses chamariam, inicialmente, com Ribot, Janet e Flournoy (apud Ellenberg, 1974), de "ideias-força", que evolveu para "lógica do sentimento" e, por fim, na etnopsiquiatria de Devereux (1974; 1980), para "emoções-força" ou valores.

Isso introduz, por um lado, grandes limitações à proposta de Blanchot-Foucault, o "princípio da recondução aos limites" para um dado paradigma, que peca por extrapolar seus lindes iniciais: mas para haver convergência ou confronto paradigmáticos e recondução, pois para os limites específicos, isso se daria a partir de onde? Seria preciso um "espaço neutro" ou então um "ponto de vista meta-". No entanto, isso seria uma metalinguagem e, portanto, evidenciaria o caráter retórico do paradigma. Passemos a explorar isso lembrando dois pontos de Kuhn (apud Geertz, 2001) que levam diretamente à questão da infiltração instaurativa dos valores nos paradigmas e à socialização dos "exemplares" por meio da "função diferenciadora da educação" em sua promoção de "especialidades". Ele afirma que a ciência normal e as revoluções são:

[...] atividades baseadas na comunidade. Para descobri-las e analisá-las, primeiro é preciso desenredar a estrutura comunitária mutável das ciências ao longo do tempo. Um paradigma não rege [...] um assunto, mas um grupo de praticantes. Qualquer estudo das pesquisas norteadas por paradigmas ou destruidoras de paradigmas deve começar pela localização do grupo ou grupos responsáveis. (p. 146)

Portanto, o paradigma é uma produção de consenso e de conhecimento como consenso a partir do grupo comunidade científica e/ ou dos intragrupos, na qual Kuhn evidencia, ao longo de todo o Posfácio, o papel formador da cultura e da linguagem na transmissão desses modelos ou "exemplares": trata-se precisamente daquilo que Durkheim (1963) designou como "função diferenciadora da educação", que nada mais é, na terminologia da Escola Cultura e Personalidade, que a transmissão das "especialidades" como elementos culturais de um grupo específico no profundo desenvolvimento dado por Linton (1961). Nesse sentido, o paradigma, como diz Kuhn, será "um sistema de exemplos compartilhados" que, a rigor, corresponde com maior precisão ao que Barthes (1968) chama de "logotécnicas" e que Bachelard (1934; 1975) chamava de "noumenotecnias". Quer dizer, isso definirá a linha em que será tratada por Kuhn a questão da incomensurabilidade, no qual des- 
pontarão as questões dos valores e das estratégias de persuasão.

Vejamos isso: para Kuhn (2000), na "matriz disciplinar”, está envolvido o paradigma por meio do "terceiro grupo de elementos que são os valores” (p. 229). Apesar do otimismo kuhniano, tentando disfarçar e não assumir o que Collingwood fizera e que, segundo o texto do próprio Kuhn, está no "conhecimento tácito" (p. 237) de Polanyi (1983), ou seja, o relativismo paradigmático, suas implicações subjetivas e sociológicas, Kuhn tenta resolver a questão da incompatibilidade e da não comunicabilidade de um modo racionalista e formalista. Assim propõe um "debate e a escolha pelo argumento das boas razões” (p. 245) Entretanto, acaba por reconhecer que essa estratégia epistemológica desemboca realmente numa questão, em última instância, valorativa, pois se trata de uma questão de sociologia da cultura e do conhecimento: a antropolítica da persuasão. Diz o próprio Kuhn (2000): “penso que persuadir alguém é convencê-lo de que nosso ponto de vista é superior e, por isso, deve suplantar o seu" (p. 249). Ora, temos aqui, por um lado, a já mencionada e irredutível questão do caráter retórico do paradigma e, por outro lado, a questão das determinações socioantropológicas e inconscientes dos quadros paradigmáticos, configurandose mediante noções como retórica sofística da persuasão, discurso competente, violência simbólica. Enfim, trata-se de um tipo de estratégia do preconceito chamada, no melhor dos casos, "antropoemia da tolerância", mas mais usualmente apresentando-se como "antropofagia dialógica” do grupo comunidade científica. Isso levará à configuração do paradigma como instituição social (Bastide, 1979), como sistema de mecanismos de defesa contra a angústia (Jacques, 1988) e, enfim, como sistemas transferenciais-contratransferenciais travestidos em metodologias científicas (Devereux, 1980). Examinemos aqueles aspectos iniciais para virmos ter aos três últimos enfoques.

Vattimo (1996) diz textualmente sobre o "teor retórico" incontornável do paradigma:
A imposição dos direitos da retórica hermenêutica, isto é, do logos-consciência comum, aos discursos demonstrativos da ciência se realiza, ao contrário, como uma radicalização da natureza essencialmente retórica da própria ciência, numa direção que, poderíamos dizer, vai da forma ao conteúdo. A natureza retórica das ciências, em sentido puramente formal, poderia ser indicada na sua efetiva dependência por paradigmas histórico-realizados: as posições de Th. Kuhn, pelo menos em linha geral, já não provocam tanto escândalo ou, em todo caso, são aquelas que uma concepção hermenêutica da ciência faz suas de melhor grado. As teorias científicas são provadas com base em observações que só são pensáveis e têm sentido no interior dessas mesmas teorias e de seus paradigmas. Nem por isso a afirmação de um paradigma é, por sua vez, um fato descritível em termos de demonstração científica. Kuhn, como se sabe, deixa substancialmente aberto o problema de como se deva pensar o evento histórico da mudança dos paradigmas; a hermenêutica pode contribuir de maneira significativa e pensar esse problema fora de uma concepção da história como puro jogo de forças ou, ao contrário, como progresso no conhecimento objetivo de uma realidade estavelmente dada. Quaisquer que sejam os problemas da concepção de Kuhn, também se pode formular o sentido geral (e, talvez, mais geralmente aceitável) da sua teoria das revoluções científicas como uma redução da lógica científica à retórica - no sentido limitado em que isso significa que as teorias científicas só se demonstram dentro de paradigmas que, por sua vez, não são "logicamente" demonstrados, mas aceitos com base numa persuasão de tipo retórico, como quer que esta se instaure de fato. (p. 137-138)

Ora, não pretendemos desenvolver a perspectiva hermenêutica sobre o paradigma (Gadamer, 1999), apesar de ela permitir, por meio das noções de "círculo hermenêutico" e de "antecipação pré-compreensiva”, escapar 
tanto ao enfoque de uma restrita sociologia do conhecimento quanto ao de uma epistemologia que ainda paga seus tributos ao racionalismo como em Bachelard (teoria dos não valores e dos obstáculos epistemológicos, ruptura epistemológica ciência-ideologia, perfil epistemológico, corracionalismo da cidadela científica). Entretanto, cabe dela reter que, nos paradigmas, desde sempre, estaremos enclausurados na linguagem (Apel, 2000), sendo o paradigma as redes de leitura e interpretação da pretensa realidade (“X”), na qual não existe algo como "a realidade" porque o acesso que a ela temos é sempre mediado pela linguagem ou função simbólica... a menos que, com ingenuidade... e má fé... nos situemos nas várias recuperações do "projeto referencial-ontológico" - cuja crítica irredutivel foi feita por Rorty (2001), em livros como A filosofia e o espelho da natureza... - e que, assim, situemo-nos antes do linguistic turn (Rorty, 1997) da filosofia analítica ou da Kehre (Hottois, 1981) da hermenêutica, antes, portanto, de Wittgenstein (1961) e de Heidegger (1967)... o que soaria como um irônico arcaísmo antropológico! Poderemos mostrar agora a retórica sofística da persuasão, presentificando-se nos paradigmas.

Desde o Protágoras de Platão, a maiêutica socrática se opõe à retórica dos sofistas, explicitada, como nos mostram Gomperz (1969) e Guthrie (1975), pelos procedimentos acoplados da erística e da peirástica, respectivamente o espírito polêmico e a arte de persuasão violenta. Esses procedimentos retóricos são encontrados nas "logotecnias" da "matriz disciplinar", definindo aquilo que Chauí (1969) chama de "discurso competente". Na burocratização da vida social e no saber administrado da/pela razão técnica, o discurso competente significa que não é qualquer um e de qualquer lugar que sabe e pode falar o que quiser. Portanto, só aquele que está investido e ocupa uma posição numa organização burocrática estará legitimado e terá a competência definida para dizer-enunciar um discurso também definido, ao qual é atribuída uma autoridade institucionalizada.

Retórica da persuasão e discurso competente aprofundam-se, em seu caráter de arbitra- riedade violenta, legitimada por uma organização tecnoburocrata do saber e por uma educação praxiológica que a operacionaliza pela noção de violência simbólica.

Lembremos, com Bourdieu (1975): "todo o poder de violência simbólica, isto é, todo poder que chega a impor significações e a impô-las como legítimas, dissimulando as relações de força, acrescenta sua própria força, isto é, propriamente simbólica, a essas relações de força”. Mostra o autor que a educação operacionaliza essa violência simbólica, em nosso caso, do arbitrário da imposição retórico-paradigmática e numa dinâmica da exclusão/inclusão compulsória pelas "estratégias de preconceito”, por meio do duplo arbitrário da ação pedagógica. Diz o autor:

1. Toda ação pedagógica (AP) é objetivamente uma violência simbólica enquanto imposição, por um poder arbitrário, de um arbitrário cultural... 1.1. A AP é objetivamente uma violência simbólica, num primeiro sentido, enquanto que as relações de força entre os grupos e as classes constitutivas de uma formação social estão na base do poder arbitrário que é a condição da instauração de uma relação de comunicação pedagógica, isto é, da imposição e da inculcação de um arbitrário cultural segundo um modo arbitrário de imposição e de inculcação (educação)... 1.2. A AP é objetivamente uma violência simbólica, num segundo sentido, na medida em que a delimitação objetivamente implicada no fato de impor e de inculcar certas significações, convencionadas, pela seleção e a exclusão que lhe é constitutiva, como dignas de serem reproduzidas por uma AP, re-produz (no duplo sentido do termo) a seleção arbitrária que um grupo ou uma classe opera objetivamente em e por seu arbitrário cultural. (p. 20-22)

Portanto, chegamos ao paradoxo das estratégias de conhecimento dos paradigmas como produção de estratégias do preconceito. 
Como processar as diferenças culturais e as alteridades grupais "não alinhadas"?

Taguieff (1987) faz um estudo exaustivo da questão acima. Lembrando a distinção dos procedimentos, descritos por Lévi-Strauss, que as sociedades e as culturas adotam para processar as diferenças e as alteridades, quais sejam, as "sociedades antropofágicas" (o Outro é reduzido ao Mesmo por manducação) e as "sociedades antropoêmicas" (o Outro é "territorializado" e cercado) - dos ghetos às prisões, manicômios, asilos, desde as "reservas" até as "instituições totais" de Goffman (1999) - para Tragtenberg (1968), a escola é uma instituição total! -, até as "pseudoespécies" de Erickson (1980) - e a escola é a menor pseudoespécie, segundo o autor -, equivalendo às "tribos" de Maffesoli (1998) - é importante ver as várias "tribos" nas escolas, no aparelho de ensino e nos congressos!), poderíamos ver aplicados dois tipos de estratégias do conhecimento-estratégias do preconceito pela ciência institucionalizada e as instituições escolares: a antropofagia dialógica e a antropoemia da tolerância ou nas palavras sintéticas de Paula Carvalho (1997):

A antropofagia dialógica é a racização amena de englobar o Outro no e pelo discurso persuasivo, forma predominante, em educação, do "homo academicus" e de muitas pedagogias dialógicas; é fundamental, em forma estereotipada, na mídia política e na indústria cultural. Costuma desembocar na antropofagia digestiva, a racização repressiva da assimilação dos outros a si-mesmo em todas as formas de aculturação. Já a antropoemia da tolerância é a racização específica do desenvolvimento "em separado": em aparência, respeita-se tanto o outro, tolerando-o, que na realidade acaba-se por isolá-lo "territorialmente", não se dando aos trabalhos dos enfrentamentos das diferenças, típico de todas as ideologias do relativismo e do ecumenismo [...]. (p. 182)

Subjacente a tais estratégias está o que a antropo-psicanálise chamou de heterofobia e que origina o etnocentrismo e suas implicações educativas e gestionárias. Como Freud (1985) já mostrara, no fundo da "estranha inquietação" (Unheimlich), está a presentificação da dimensão do Inconsciente ou da Sombra Coletiva (em termos junguianos, cf. Zweig; Abrams, 1993), permeando as redes cognitivas na interação sociocultural. A partir daqui, desenvolvem-se duas noções que, infelizmente, não poderemos aprofundar: a noção de ritual de opressão, desenvolvida por Devereux (1974), e a noção de esquema mental inquisitorial, desenvolvida por Paula Carvalho (1987-1988). São noções de grande valor antropolítico conduzindo diretamente àquilo que é o cerne da questão paradigmática e da socialização educativa: o que é valor?

Se no salutar relativismo epistemológico de Kuhn (ainda mais se relido e promovido a uma das facetas do anti-antirrelativismo de Geertz), os paradigmas são sistemas de valores e crenças, é precisamente na noção de valor que vemos confluírem o caráter de instituição social dos sistemas de pensamento e seu teor inconsciente como sistemas projetivos, pois mesmo nos sistemas cognitivos, os valores são o sustentáculo da ação que lhes é específica, porque mesmo no valor cognitivo, está indissoluvelmente imbricado o afeto, isto é, a catexis torna-os "emoções-força". Isso pode ser rastreado por meio de duas vertentes, seja uma sociologia do conhecimento que chegue a uma axiologia, seja a uma axiologia que venha a ter a uma teoria da ação social.

$\mathrm{Na}$ primeira vertente, Gurvitch (1962) nos mostra que, dentre os enfoques das morais do sentimento até as teorias modernas dos valores, que permeiam uma sociologia da cultura e uma sociologia do conhecimento, destaca-se o enfoque de Max Scheler (1955; 1960), um dos fundadores tanto da sociologia do conhecimento, quanto da axiologia. Precisamente na segunda parte do livro, capítulo IV e $\mathrm{V}$, estão as proposições fundamentais de Scheler que, ademais, Karl Mannheim (1952) elabora no capítulo IV. Por meio de ambos os textos, poderíamos sintetizar: (1) os valores são a priori 
emotivos, isto é, qualidades imediatas e irredutíveis das vivências na experiência emotiva, sendo consequentemente alógicos e irracionais; subtraem-se, portanto, a uma abordagem mediante as leis lógicas porque, precisamente, são dados imediatos das vivências do Lebenswelt (mundo da vida) que condicionam, de modo preciso, as elaborações cognitivas; (2) há um pluralismo de valores, que Max Weber chamava de "politeísmo de valores", que são tantas orientações possíveis da ação social segundo os vetores diversos que os sistemas de conhecimento acolhem, pois a sociedade e a cultura, por intermédio dos grupos, selecionam esses vetores de orientação e estabelecem uma hierarquia de valores de tal modo que a famosa "neutralidade axiológica" de Max Weber (1965) é impossível: todo sistema de conhecimento e pensamento é orientado a partir desses a priori emotivos plurais. Por isso, os franceses da escola da "lógica do sentimento" falam em "emoções-força”. Em suma, os sistemas cognitivos são orientados por tais a priori emotivos. E isso de tal modo que o afeto, como dirá P. Janet (2000), ou a libido, como dirá seu discípulo Freud, fundam tais a priori emotivos. Lembremos, num parêntese, por razões de consistência no rastreamento genético-conceitual, que há um escalonamento entre afeto/libido/inconsciente: trata-se do trajeto que vai de Janet, com $O$ automatismo psicológico, publicado em 1889, ao Freud da "econômica" e das "tópicas", como mostraram, na gênese conceitual do trajeto, Starobinski (1970) e Reich (1976), publicado nos Primeiros Escritos. Em suma, o inconsciente está na base da elaboração paradigmática: é a "indução arquetipal do conceito pela imagem", como diz Durand (1969, p. 62).

É precisamente isso que será elaborado na segunda vertente, ou seja, na axiologia de Kluckhohn (1968; 1962), dentro dos marcos da teoria da ação do grupo de Parsons. Kluckhohn (1968) define o valor como uma concepção explícita, mas geralmente implícita, própria de um indivíduo ou característica de um grupo sobre o desejável que é determinante na sele- ção dos modos, meios e fins de ação acessíveis. Fazendo uma análise detalhada dessa definição, que não reteremos aqui, o autor mostra que essa "construção lógica" é sempre permeada pelo desejo, afeto ou catexis, e isso de tal modo que o valor - que o autor sempre prefere dizer "valor de grupo" e não valor cultural - não passa de uma racionalização para uma catexis. Distinguindo entre os valores cognitivos, valores expressivos e valores estimativos, posto que a catexis é evidente nos dois últimos, Kluckhohn (1962) desenvolve ampla argumentação sobre o componente catético ou afetual dos valores cognitivos. Evidenciando que, via de regra, os valores coincidem com a "cultura encoberta" do grupo - depois o autor designou-a como "cultura implícita" ou "cultura latente" sob o influxo das investigações antropopsicanalíticas -, Kluckhohn mostra o funcionamento da dimensão inconsciente na cultura do grupo e nas instituições sociais, por onde os sistemas cognitivos são estruturas de pressupostos de teor afetivo, catético ou inconsciente.

Poderemos, então, compreender essa dimensão socioantropológica dos paradigmas articulada à dimensão antropo-psicanalítica destes a partir de Bastide (1979), Jacques (1988) e Devereux (1980), compreendendo, portanto, o caráter "arbitrário" da persuasão retórica nos paradigmas: trata-se de uma indução inconsciente de racionalizações e polêmicas como estratégias de conhecimento fundada na inquestionabilidade dos a priori emotivos ou das emoções-força que são os valores. A educação simplesmente comunica esses valores de grupo transmitindo paradigmas. A questão de sua transformação envolve, precisamente, um trabalho sobre a dimensão fantasmática da ação social como veremos em Jacques (1988).

Frente ao que já foi dito, poderemos compreender claramente, com Bastide (1979), que os paradigmas, os sistemas cognitivos e os planejamentos são instituições sociais. Diz o autor:

A antropologia aplicada, tal como a definimos, considera os modelos de intervenção, 
que obedecem às regras metodológicas das ciências, como instituições sociais, em pé de igualdade com a família, o econômico ou a política. Sem dúvida trata-se de instituições de ação inovadora, mas de instituições, todavia, da mesma natureza das outras, que são instituições de natureza cristalizada. Logo, elas podem ser objetos de análises similares. Em suma, propomos considerar os "projetos" de ação como "obras culturais" de natureza idêntica a todas as outras obras do homem, do mesmo modo que seu sistema de parentesco e sua organização em castas ou classes. Como outras obras culturais, podemos destacar os fins, os valores (ocultos ou manifestos), as leis de funcionamento, as cadeias de ligações entre as partes [...], onde as determinações finalmente inconscientes podem ser encontradas nos valores que permanecem latentes e que foram aí traduzidos como objetivos. (p. 164)

Portanto, paradigmas, sistemas de conhecimento e planejamentos são instituições sociais que, lembremos, para o grupo de Parsons, são "pautas valorativas da ação", cuja dimensão inconsciente passamos a destacar por meio da socianálise de Jacques (1988) e da etnopsiquiatria/etnopsicanálise de Devereux (1974; 1980).

Apoiando-se nos estudos de Melanie Klein (1989) sobre a identificação projetiva e introjetiva em sua ação recíproca e no mecanismo originário de defesa contra a ansiedade pelo jogo entre agressão e reparação nos ataques ao seio materno e aos seus deslocamentos amplificados nos objetos sociais, Bion (1987) aprofundou-se no estudo dos grupos em sua socianálise do protomental, definindo as "hipóteses de base" responsáveis pelos vínculos nos pequenos grupos, e Jacques (1988) amplia o estudo das dinâmicas psíquicas inconscientes ativadas nas instituições e nos grupos sociais.

Jacques (1988) diz que os pontos fundamentais consistiriam em desenvolver a tese que os sistemas de pensamento como instituições sociais são mecanismos de defesa potenciados, mobilizados contra a emergência da ansiedade persecutória e depressiva na vida dos grupos que elaboram tais sistemas. Os mecanismos de identificação projetiva e introjetiva atuam no processo de vinculação entre o comportamento individual e o comportamento grupal. Portanto, os indivíduos se valem inconscientemente das instituições e, pela associação e pela cooperação, inconscientemente reforçam as defesas contra a emergência da angústia originária. Assim, esse autor insiste na discriminação entre a forma e o conteúdo social fantasiado/fantasmatizado de uma instituição:

A fantasia/o fantasma é usado no sentido de uma atividade intrapsíquica completamente inconsciente [...]. Desse ponto de vista, o caráter da instituição é determinado e especificado não somente por suas funções explícitas ou inconscientemente avalizadas e aceitas, mas também por suas múltiplas e não reconhecidas funções no plano da fantasia/fantasma. (p. 306)

Qualquer "ataque" ou discordância ou pluralismo epistemológico despertam a "angústia originária” e mobilizam a radicalização e intolerância de um sistema cognitivo/paradigma como mecanismo de defesa potenciado e reforça sua impositividade excludente como violência simbólica. Como lembra Don Juán a Castaneda (1968), não se pode puxar o tapete... ninguém tolera perder o pé, ou melhor, sequer aguenta ficar sem referenciais ordinários... Em virtude disso, muitos problemas sociais são insolúveis e as mudanças extremamente difíceis, pois a mudança na estrutura ou na cultura evidentes, com o objetivo de resolver um problema, pode ser ineficiente simplesmente por não se ter atingido a estrutura fantasmática de sustentação da coesão social dada, por permanecerem invariadas as relações inconscientes no vínculo social. Jacques (1988) afirma:

As razões que explicam a impossibilidade de mudar muitos conflitos sociais e tensões 
de grupo podem ser mais claramente apreciadas quando vistas como "resistências" de grupos de pessoas que inconscientemente se agarram às instituições de que dispõem, já que as mudanças nas relações sociais ameaçariam perturbar defesas sociais preexistentes contra a ansiedade psicótica. (p. 313)

$\mathrm{Na}$ medida em que os paradigmas são instituições sociais, são sistemas de pensamento e são sistemas sociais mobilizados contra a emergência da ansiedade psicótica ou da angústia originária: eles são mecanismos de defesa potenciados e esse é seu "teor inconsciente" como sistemas de pressuposições absolutas ou sistema de valores, pois falamos sempre a partir de uma tábua de valores que nos situa e permite que situemos os outros com relação a nós... Nessa medida, a possível ação transformadora da educação acha-se limitada...

Devereux (1980) detecta o caráter perverso e o funcionamento inconsciente dos paradigmas, sistemas de pensamento e metodologias científicas, amplificando as considerações anteriores. Diz que o estudo científico do homem:

1. é obstado pela angústia provocada pelo recobrimento entre o tema de estudo e o observador;

2. esse recobrimento exige a análise do lugar e da natureza da partilha entre ambos; 3. essa análise deve compensar a parcialidade da comunicação entre o tema e o observador a nível consciente mas

4. não deve ceder à tentação de compensar a plenitude dessa comunicação a nível inconsciente,

5. a qual desperta a angústia e, assim, também, as reações de contratransferência

6. que deformam a percepção e a interpretação dos dados e

7. produzem resistências e contratransferência que assumem as feições de metodologia, provocando novas deformações sui generis.

8. Desde que a existência do observador, sua atividade de observador e suas angústias (mesmo na auto-observação) produzem deformações que são, não só técnica mas também logicamente impossíveis de serem eliminadas, 9. toda metodologia eficaz em ciência do comportamento deve tratar tais perturbações como sendo os dados mais significativos e mais característicos na pesquisa nessa ciência. 10. Ela deve explorar a subjetividade inerente a toda observação como a via régia para uma autêntica objetividade, e não fictícia.

11. Essa objetividade deve ser definida em função daquilo que é realmente possível, mais do que em função do que "deveria ser".

12. Negligenciadas ou embelezadas de modo defensivo pelas resistências e contratransferência, vestidas como metodologias, essas "perturbações" tornam-se a fonte de erros incontrolados e incontroláveis ao passo que, 13. quando são consideradas como dados fundamentais e característicos das ciências do comportamento, são mais válidas e mais aptas a produzir tomadas de consciência que qualquer outro tipo de dados. Em suma, os dados das ciências do comportamento suscitam uma angústia contra a qual nos defendemos por meio de uma pseudometodologia inspirada pela contratransferência; tal manobra é responsável por quase todos os erros das ciências do comportamento. (p. 16-17)

Derradeira objeção ao mito da objetividade científica dos paradigmas e à correlata função lógico-racional e axiologicamente neutra da educação na elaboração paradigmática e em sua transmissão, bem como da famosa "ruptura epistemológica” bachelardiana-althusseriana ciência/ideologia: o paradigma é uma fantasia, ou melhor, tem o funcionamento de uma fantasia. Hillman (1999), muitas vezes, diz "de acordo com a fantasia de Kérényi", "de acordo com a fantasia de Freud", "de acordo com minha fantasia”, querendo significar o teor de fantasia da teoria ou paradigma. Entretanto, o trajeto já se preparara para ele. Ele tem a coragem de enunciar o problema epistemologicamente, tirandothe as consequências e propondo, assim, de 
modo salutar, uma abordagem "poiética" da questão paradigmática, por onde liberta, ou "comuta", a estrutura fantasmática dos paradigmas em estruturas fantasiosas, distinguindo não só fantasma e fantasia, mas propondo, dessa feita, uma reversão "positiva" da colocação do problema. Vejamos como poderíamos esboçar as etapas desse trajeto.

Paula Carvalho (1985) já trabalhava longamente essa comutação de uma fantasmática numa "fantástica transcendental", projeto que Durand $(1969 ; 1983)$, numa antropologia do imaginário e numa sociologia profunda, herda de Novalis e que tanto ele como Paula Carvalho, por caminhos diversos, ampliam. No denso estudo sobre a antropologia psicanalítica de Géza Róheim, Paula Carvalho (1987/ 1988) mostra de modo detalhado como o fantasma equivale às "formações reativas" (assim, o uso "perverso" dos paradigmas na luta ideológica) e como a estrutura fantasmática das formações reativas (portanto, de todas as formas de ideação construídas por tal mecanismo) constituem o "superego social". Elas funcionam pela produção da estase libidinal pela repressão. Diferentemente, as sublimações são fantasias, usando um termo de Marcuse (1968), ou sublimações não repressivas ou dessublimações. Elas adquirem o caráter do "ludismo transicional" que Winnicott (1971) trabalhou longamente nos "objetos transicionais" do "espaço potencial" da "região intermediária” entre os objetos primários, regidos pelo princípio do prazer, e os objetos secundários, regidos pelo princípio da realidade/rendimento e desempenho. Essa região alocada ao modo de jogos de linguagem com o mito, a arte, a magia e a religião, amplificarse-ia, agora, com a inclusão da própria ciência ou da imaginação científica. Numa elaboração aprofundada da problemática, cujos passos não podemos aqui refazer, André Green (1980) elabora a noção de “objetos terciários”, para exatamente recobrir os objetos de tal região em tal dinamismo "poiético": mito e ciência são, doravante, "objetos transicionais coletivos". Portanto, os paradigmas podem ser fantasmas ou fantasias... de acordo com as políticas culturais e lutas ideológicas em sua retórica de jogos de linguagem, enfim, de acordo com uma antropolítica, uma política do Homem adotada. Citemos um texto de Dadoun (1972), em seu estudo sobre a antropologia psicanalítica de Géza Róheim, que anteciparia as etapas acima mencionadas:

[...] também é possível designar como "transicionais" objetos "intelectuais" ou "representacionais" ou "poéticos", isto é, um sistema de pensamento, uma teoria, uma forma plástica, um procedimento operatório, a figura de um mestre, com que o sujeito mantém tipos de relações mais ou menos profundamente unidas ao próprio trabalho criativo, o que fora até agora malmente designado por "influência". Um "campo transicional representacional" ou um "campo transicional poético" - aqui compreendido tudo que se refira à criatividade - seria, assim, delimitado, tornando-se no espaço de circulação de uma valência subjetiva, narcisista - investimento libidinal do ego sobre tal aspecto da pessoa ou tal produto ou processo de sua criati-vidade - e de uma valência objetiva, objetal - investimento de um produto ou de um processo ou de uma forma ou de uma figura exterior; ou, naturalmente, nas duas vertentes, contra-investimentos. 0 progresso de uma elaboração estaria ligado à capacidade de fazer circular e equilibrar tais investimentos ou contra-investimentos, dinamicamente percorrendo tal campo transicional. (p. 72)

Para concluir, poderíamos nos perguntar como os paradigmas poderiam ser usados como campo de objetos transicionais num ludismo cultural e educativo. De modo indicativo e remissivo, poderíamos lembrar que formam uma única constelação, nas sociedades contemporâneas, o politeísmo de valores, o pluralismo cultural, o policulturalismo e as hibridações ou hibridismos (Canevacci, 1996). 
Nesse sentido, não há como recusar um perspectivismo retórico e uma relativização, que fariam um jogo entre o "relativismo ontológico" de Feyerabend (2007), o "tudo vale" e o "etnocentrismo crítico" de Martino (1980). Teríamos um relativismo ontológico mitigado ou um relativismo epistemológico nos quais os epistemas seriam tratados no ludismo transicional.

Para Monique Augras (1989), as elaborações de Paula Carvalho estariam sob a égide de um politeísmo epistemológico e de certa visão do pragmatismo em pesquisa. Pensamos que, ao lado do já mencionado "princípio de recondução aos limites” (Blanchot-Foucault,
1963), do "princípio de saturação dos limites" (Sorokin-Durand, 1969) e de uma "filosofia da criação científica” (Moles, 1998), em termos epistemológicos, Paula Carvalho relativizou os paradigmas em heurísticas e elaborou uma cartografia dessas heurísticas em antropologia das organizações educativas (Paula Carvalho, 1990) e em culturanálise de grupos (Paula Carvalho, 1991). Enfim, trabalhando com os conceitos de educação fática e ação cultural em vários projetos, esse autor mostrou como, no nível microssocial de vários grupos socioculturais, poderiam ser utilizadas as propostas de Bion (1987) e de Winnicott (1971).

\section{Referências bibliográficas}

APEL, K. O. Transformação da filosofia I e II. São Paulo: Loyola, 2000.

BACHELARD, G. Le nouvel esprit scientifique. Paris: PUF, 1934. . Le rationalisme appliqué. Paris: PUF, 1975.

BARTHES, R. Le dégré zéro de l'écriture. Paris: Denoë//Gonthier; Médiations, 1968.

BASTIDE, R. Antropologia aplicada. São Paulo: Perspectiva, 1979.

BAUDOUIN, Ch. L'oeuvre de Jung et la psychologie complexe. Paris: Payot, 1963.

BION, W. R. Recherches sur les petits groupes. Paris: PUF, 1987.

BOURDIEU, P. A reprodução: elementos para uma teoria do sistema de ensino. São Paulo: Francisco Alves, 1975.

CANEVACCI, M. Sincretismos: uma exploração das hibridações culturais. São Paulo: Studio Nobel; Instituto Cultural Ítalo-Brasileiro, 1996.

CHAUÍ, M. S. Cultura e democracia: o discurso competente e outras falas. São Paulo: Moderna, 1969.

COLLINGWOOD, R. C. A ideia de história. Lisboa: Presença; Martins Fontes, 1978.

. An essay on metaphysics. Oxford: Clarendon Press, 1940.

PETITO, J. (Éd.). Logos et théorie des catastrophes: à partir de l'oeuvre de René Thom. COLLOQUE DE CÉRISY. Genève: Patiño, 1988.

DADOUN, R. Géza Róheim et l'essor de l'anthropologie psychanalytique. Paris: Payot, 1972.

DEVEREUX, G. De l'angoisse à la méthode dans les sciences du comportement. Paris: Flammarion, 1980.

La psicoanalisi e la storia. Una applicazione alla storia di Sparta. In: BRAUDEL, F. (Ed.). La storia e le altre scienze sociale.

Bari: Laterza, 1974. p. 296-332. 
DURAND, G. Les structures anthropologiques de l'imaginaire: introduction à l'archétypologie générale. Paris: Bordas, 1969.

Mito e sociedade: a mitanálise e a sociologia das profundezas. Lisboa: A Regra do Jogo, 1983.

DURKHEIM, E. Educação e sociologia. Rio de Janeiro: Forense, 1963.

ERICKSON, E. Ontogénie de la ritualisation. In: HUXLEY, J. (Ed.). Le comportement rituel chez l'animal e I'homme. Paris: Gallimard, 1980.

FEYERABEND, P. Contra o método. São Paulo: Editora UNESP, 2007.

FOERSTER, H. von. Notes pour une epistémologie des objets vivants. In: MORIN, E.; PIATELLI-PALMARINI (Éds.). L'unité de I'homme: le cerveau humain. Colloque de Royaumont. Paris: Seuil, 1974.

FREGE, G. Écrits logiques et philosophiques. Paris: Seuil, 1971.

FREUD, S. L'inquiétante étrangété et autres essais. Paris: Gallimard, 1985.

GADAMER, H. G. Verdade e método. Petrópolis: Vozes, 1999.

GEERTZ, Cl. Nova luz sobre a antropologia. Rio de Janeiro: Jorge Zahar, 2001.

GOFFMAN, E. Manicômios, prisões e conventos. São Paulo: Perspectiva, 1999.

GOMPERZ, Th. The greek thinkers. London: J. Murray, 1969. (v. I, Book III, chap. V)

GREEN, A. Le mythe: un objet transitionnel collectif. Temps de la réflexion, v. I. p. 99-131, Paris: Gallimard, 1980.

GURVITCH, G. Morale théorique et science des moeurs. Paris: PUF, 1962.

GUTHRIE, W. A history of greek philosophy. Cambridge: Cambridge University Press, 1975. (v. III).

HEIDEGGER, M. Essais et conférences. Paris: Gallimard, 1967.

HILLMAN, J. 0 livro do puer: ensaios sobre o arquétipo do puer aeternus. São Paulo: Paulus, 1999.

HOLTON, G. La imaginación científica. México: FCE, 1989.

HOTTOIS, G. Pour une métaphylosophie du langage. Paris: Vrin, 1981.

JACQUES, E. Sistemas sociais como defesas contra a ansiedade persecutória e depressiva. Revista da Faculdade de Educação, v. 14 , n. 2, p. 303-313, 1988.

KLEIN, M. Essais de psychanalyse (1921-1945). Paris: Payot, 1989.

KLUCKHOHN, Cl. Culture and behavior. New York: The Free Press of Glencoe, 1962.

KLUCKHOHN, Cl. Los valores y las orientaciones de valor en la teoría de la acción. In: PARSONS, T. (Dir.). Hacia una teoría general de la acción. Buenos Aires: Kapelusz, 1968.

KUHN, T. A estrutura das revoluções científicas. São Paulo: Perspectiva, 2000.

LAKATOS, I. (Org.). A crítica e o desenvolvimento do conhecimento. São Paulo: Cultrix; EDUSP, 1979.

LINTON, R. 0 homem: uma introdução ao estudo antropológico. São Paulo: Mestre Jou, 1961.

MAFFESOLI, M. 0 tempo das tribos: o declínio do individualismo nas sociedades de massa. Rio de Janeiro: Forense Universitária, 1998.

MANNHEIM, K. Essays on the sociology of knowledge. London: Routledge \& Kegan Paul, 1952. 
MARCUSE, H. Eros e civilização: uma crítica filosófica ao pensamento de Freud. Rio de Janeiro: Jorge Zahar, 1968.

MARTINO, E. de. Furore símbolo valore. Milano: Feltrinelli, 1980.

MAURON, Ch. Des métaphores obsédantes au mythe personnel: introduction à la psychocritique. Paris: Lib. J. Corti, 1968.

MAUSS, M. Sociologie et anthropologie. Paris: PUF, 1986.

MORIN, E. Ciência com consciência. Rio de Janeiro: Bertrand do Brasil, 2000.

PAULA CARVALHO, J. C. de. Imaginário e organização. Revista de Administração de Empresas. São Paulo: EASP/FGV, v. 25, n. 3, p. 31-48, 1985.

A inquisição e o problema da alteridade: uma abordagem da antropologia profunda. Revista de Ciências Sociais, Fortaleza: UFC, v. 18/19, n. 1/2, 1987/1988.

Etnocentrismo: imaginário, inconsciente e preconceito no universo das organizações educativas. Interface-Comunicação, Saúde, Educação, Botucatu: Fundação UNI/UNESP, v. 1, n. 1, 1997.

Antropologia das organizações e educação: um ensaio holonômico. Rio de Janeiro: Imago, 1990.

A culturanálise de grupos: teoria e heurística em educação fática. São Paulo: FEUSP, 1991. (Ensaio para Titulação em Antropologia das Organizações e Educação)

PRADO COELHO, E. Os universos da crítica. Lisboa: Ediç̃̃es 70, 1982.

REICH, W. Les concepts de pulsion et de libido, de Forel à Jung. Paris: Payot, 1976. Premiers Écrits I.

RORTY, R. Escritos filosóficos I: objetivismo, relativismo e verdade. RJ: Relume Dumará, 1997.

A filosofia e o espelho da natureza. RJ: Relume Dumará, 2001.

RUSSEL, B. Signification et vérité. Paris: Flammarion, 1990.

SCHELER, M. Le formalisme en éthique et l'ethique matériale des valeurs. Paris: Gallimard, 1955.

El saber y la cultura. Santiago de Chile: Editorial Universitaria, 1960.

SCHÜTZ, A. El problema de la realidad social. Buenos Aires: Amorrortu, 1978.

Fenomenología del mundo social: introducción a la sociología comprensiva. Buenos Aires: Paidòs, 1972.

Collected papers. The problem of social reality. The Hague: Martinus Nijhoff, 1962-66.

STAROBINSKI, J. Remarques sur l'histoire des fluides imaginaires: des esprits animaux à la libido. In: STAROBINSKI, J. La rélation critique. Paris: Gallimard, 1970. p. 92-131.

TAGUIEFF, P. A. La force du préjugé: essai sur le racisme et ses doubles. Paris: Gallimard, 1987.

TOULMIN, S. La comprensión humana: Ios usos colectivos y la evolución de los conceptos. Madrid: Alianza Universidad, 1977. L'explication scientifique. Paris: Armand Colin, 1973.

TRAGTENBERG, M. A escola como organização complexa. In: GARCIA, W. (Org.). Educação brasileira: organização e funcionamento. São Paulo: McGraw Hill, 1968. p. 62-78.

VATTIMO, G. 0 fim da modernidade: niilismo e hermenêutica na cultura pós-moderna. São Paulo: Martins Fontes,1996.

WEBER, M. Essais sur la théorie de la science. Paris: Plon, 1965. 
WINNICOTT, D. W. Jeu et réalité: I'espace potentiel. Paris: Gallimard, 1971.

WITTGENSTEIN, L. Tractatus logico-philosophicus suivi de Investigations philosophiques. Paris: Gallimard, 1961.

ZWEIG, C.; ABRAMS, J. Ao encontro da sombra: o potencial oculto do lado escuro da natureza humana. São Paulo: Cultrix, 1993.

Recebido em 12.06.08

Aprovado em 07.05.08

Denis Domeneghetti Badia, mestre em Ciências da Comunicação pela ECA-USP e doutor em Educação pela FEUSP, é professor do Departamento de Ciências da Educação e do Programa de Pós-Graduação em Educação da Faculdade de Ciências e Letras da UNESP/Araraquara e diretor do Centro Interdisciplinar de Pesquisas sobre o Imaginário (CIPI - FCL UNESP - SCAr). 